\title{
Fertility Determinan in Sudan: Analysis of Multiple Indicator Cluster Survey, 2014
}

\author{
Mustafa Elnagi Elsamani Hassan ${ }^{1}$, Sukamdi² $^{2}$ and Agus Joko Pitoyo² \\ ${ }^{1}$ Department of Population and Human Studies, \\ Faculty of Geographical and Environmental Sciences, Khartoum University, Sudan, \\ ${ }^{2}$ Faculty of Geography, Universitas Gadjah Mada, Yogyakarta \\ Correspondence: Mustafa Elnagi Elsamani Hassan \\ (e-mail: mustafa2031991@gmail.com \& mustafa2031991@uofk.edu)
}

\begin{abstract}
Sudan has continuously reported high fertility rates. While the influence of both underlying and proximate determinants is well documented in various studies worldwide, there's a lack of recent information on their influence on fertility in Sudan. Therefore, the objective of this study to examine the levels, patterns and determinants of fertility in Sudan. The analyses were based on 2014 Sudan Multiple Indicators Cluster Survey (SMICS) data. The SMICS data is nationally representative data. The survey sampled 18,302 women across the country, collecting information on females aged 15-49 years. The analysis was based on the Bongaarts Model. Results show that post-partum infecundability has the largest effect in reducing fertility in Sudan (30.7 per cent or 4.7 birth) followed by marriage (27.5 per cent or 4.3 birth) and contraceptive (7.8 per cent or 1.2 birth). The findings of study shown also that significant differences between education, wealth, and place of residence. This means that the increase in education, especially higher education, improve the wealth status and living in urban areas seem to have a great influence toward fertility education in Sudan. Also, it agreed that there is a regional fertility differential associated with social and economic development in the different region and states. Therefore, in order to manage fertility in Sudan, policies and programmes should consider the effects of marriage, postpartum infecundity, contraception, education, and wealth on fertility. Lack of such targeted interventions, population growth will remain a challenge in Sudan.
\end{abstract}

Keywords: fertility; proximate determinants; underlying determinants

\section{Introduction}

Fertility in Sudan stood at 5.2 births per woman in 2015 (MICS, 2015), more than double the replacement level. This high fertility combined with declining mortality with 52 infant mortality rate (MICS, 2015). This has resulted in rapid population growth 2.4 percent per year (UNFPA, 2011), and the United Nation projects the Sudan population to grow from 38 million in 2015 to 80 million in 2050 and 138 million in 2100 (UN, 2017). Such unprecedented population increase creates a range of social, economic, and environmental challenges and makes it more difficult for the country to raise living standards (UNFPA, 2011). Hence the growing interest in demographic trends in Sudan among policymakers. 
Sudan is considered to be one of the countries with high fertility and population growth rates wide world. However, in recent years it has been observed that fertility level has been declining. According to United Nations data (2015), the Total Fertility Rate (TFR) in Sudan dropped from 6.65 during the period of $1955-1960$ to 4.46 children per woman of childbearing age during the period of 2010-2015 2.2 drop in 55 years (UN, 2015). In contrast to the majority of African countries, fertility decline in Sudan is not associated with contraceptive use, since Sudan is predominantly, a non-contracepting population. According to surveys conducted in Sudan indicate that the percentage of women age 15-49 years currently married who are using (modern or traditional) contraceptive method increased from 4.6 per cent (SFS 1978-1979) to 8.7 per cent (SDHS 1989-1990). This percentage according to the current data have experienced an increase from 9 per cent (SHHS, 2010) to 12.2 per cent (SMICS 2014). However 12.2 per cent is still a low percentage of using contraception. This because there is a lot of challenges and dilemmas for women to utilize contraception methods are culture, religion, economic, politic, urban-rural availability of services and man dominant in decision-making (Ibnouf, et.al., 2007; Ahmed, 2016).

Generally, it is understood that changes in fertility are mainly a result of changes in the fertility rates. However, there are various factors that have a bearing or influence on birth rates, and in turn, fertility rates. These factors are termed underlying and proximate determinants (Bongaarts and Potter, 1983; Davis and Blake, 1956). The interaction of these factors and births result in either an increase or decrease in births and ultimately fertility rates and this has been shown in various studies (Chola, 2013; Tey, et.al., 2012; Moses and Kayizzi, 2007).
Studies by Davis and Blake (1956) and Bongaarts and Potter (1983), among others, have shown that fertility rates are influenced by various factors among which are proximate determinants. Proximate determinants of fertility include those factors that directly influence fertility. Bongaarts (2015) argued that if accurately measured and modelled, the proximate determinants should explain 100 per cent of the variation in fertility. Davis and Blake (1956) produced the first systematic classification of the proximate determinants of fertility through which economic, social and other factors must operate to control fertility. Bongaarts and Potter (1983) formalized and operationalized the proximate determinants framework so it could be routinely applied to widely available data. Thus, the Bongaarts and Potter framework permitted an empirical determination of the relative importance of factors affecting fertility in different populations and over time. Specifically, Bongaarts and Potter (1983) showed that most fertility variation could be accounted for with just four proximate determinants. These proximate determinants were i) marriage (reflecting regular sexual intercourse and exposure to the risk of pregnancy), ii) the frequency and intensity of breastfeeding (the primary determinant of the length of postpartum infecundability), iii) the use and effectiveness of contraception, and iv) the use of abortion. This implies that if one proximate variable changes, holding all others constant, fertility will change. Much research on high or declining fertility is benefited from this simple but powerful framework (Dharmalingam, et.al., 2015).

Various studies employing this framework, such as studies by Islam (2017), Lailulo \& Susuman (2017), Chola \& Michelo (2016), Islam, et.al. (2015), Majumder \& Ram (2015), Hossain \& Karim (2013), 
Khan \& Mahjabeen (2011), and Moses \& Kayizzi (2007), have shown the effect and influence that proximate determinants have on fertility. For example, an analysis of factors affecting fertility in Bangladesh showed that contraception emerged as the highest fertility reducing factor. It was also shown that although the fertility-reducing marriage was increasing, its effect was offset by the declining trend in the lactational infecundability period (Khan \& Mahjabeen, 2011). Similarly, Islam, et.al. (2015) found that contraceptive use playing the key role in fertility change in Bangladesh. Opposed of these, Hossain \& Karim (2013) observed that marriage and lactational infecundability have a vital role to reduce fertility in Bangladesh followed by contraception use. An application of Bongaarts model to surveys data of Oman in the period between 1988 to 2008 revealed that marriage patterns have the largest fertility inhibiting effect followed by postpartum infecundability and contraception (Islam, 2017).

Analysis by Lailulo \& Susuman in 2017 in Ethiopia found that post-partum infecundability had a great fertility reduction effect compared with the contraception and marriage in rural Ethiopia. Moses and Kayizzi (2007) analyzed the 1995 and 2001 Uganda Demographic and Health Surveys (UDHSs) using Bongaarts' model in an effort to explain fertility decline in urban areas of Uganda. Moses and Kayizzi found that the change in the proportion of married women and postpartum infecundability due to breastfeeding had the greatest inhibiting effect on fertility in urban areas of Uganda, while contraception use contributed the least. Another study conducted in Zambia to analysis of the 2007 Zambia Demographic and Health Survey data using Bongaarts' model showed that marriage had the largest inhibiting effect on natural fertility from biological maximum of 19.10 children (40 per cent), followed by post-partum infecundity (22 per cent) contributed towards reducing fertility while contraception was observed the lowest inhibitor of fertility (Chola \& Michelo, 2016).

In Sudan, Adam (2007) and some other studies (Mahfouz, 2006 and Eltigani, 2000) showed marriage patterns was the most important fertility inhibiting factor 1979 to 1999 followed by postpartum infecundability and contraception. Although the influence of proximate determinants has been documented in Sudan, no study has been conducted recently to show what the current scenario is with regard to proximate determinants and how this understanding interacts prevailing or previously conducted interventions as they related to maternal and child health survival strategies. It is necessary to determine how these activities may have influenced changes in the effects of proximate determinants on fertility. The influence of these determinants may have changed from what was observed previously and thus may provide more recent information on the current effects of proximate determinants on fertility levels in Sudan.

Therefore, this study was aimed at examining the levels, patterns, differentials of proximate determinants of fertility in Sudan using data from 2014 Sudan Multiple Indicators Cluster Survey (SMICS). This is the most recent (MICS) done in Sudan. Findings from this study will provide information on proximate determinants of fertility in Sudan and how they are linked and interact with health promotion actions for maternal survival programmers relevant to fertility management. The following sections describe the methods, results and discussion, and conclusions. 


\section{Materials and Methods}

\section{The Data}

This study was a cross-sectional study. Data used in this study was based on Sudan Multiple Indicator Cluster Survey (MICS), 2014 which is a nationally representative sample survey of Sudanese households with a stratified representative sample of 18,302 aged 15 and 49 years were successfully interviewed. The survey provides statistically sound and internationally comparable data essential for developing evidence-based policies and programmes, and for monitoring progress toward national goals and global commitments. The survey collected various information concerning women background, marriage, fertility and birth history, desire for last birth, maternal and newborn health, post-natal health checks, illness symptoms, contraception and unmet need, domestic violence, female cutting, and HIVIAIDS. The study focused on analyzing female fertility data. The outcome variable was lie births recorded in the years preceding the survey, that is, whether the women gave birth to a live baby in the year before the SMICS was conducted. Analysis focused on proximate determinants as collected in the SMICS. This included marriage patterns, contraception, postpartum infecundability and abortion.

\section{The Model}

Data analysis was done by applying Bongaarts model for analyzing proximate determinants of fertility to female fertility data from the 2014 SMICS. Bongaarts (1982) and Bongaarts and Portter (1983) quantifies the contribution of four proximate determinants of fertility, namely, marriage, contraception, abortion, and postpartum infecundability. The equations below summarize the basic structure of the Bongaarts model by relating the fertility measure to the proximate determinants. Equations are shown as follows:

$$
\begin{gathered}
\text { TFR }=C_{m} \times C_{c} \times C_{a} \times C_{i} \times T F \ldots \ldots \ldots \ldots \ldots \ldots(1) \\
T M=C_{c} \times C_{a} \times C_{i} \times T F \ldots \ldots \ldots \ldots \ldots \ldots \ldots \ldots \ldots \ldots \ldots \ldots \ldots \ldots \ldots
\end{gathered}
$$

Where TFR is the Total Fertility Rate. This is the average number of children to which a woman will have given birth by the end of her reproductive years (by age 50 ) if current fertility rates prevailed. TF is the Total Fecundity Rate. This is the number of birth women would have at the end of reproductive age if she were to bear children at prevailing age-specific marital fertility rates and remained, married during the entire reproductive period. TN is Total Natural Marital Fertility Rate. This is equal to the total marital fertility rate in the absence of contraception and induced abortion. TF is the average number of live births expected among women who during their entire reproductive period, remain married, do not use contraception, do not have any induced abortion and do not breastfeed their children. with average 15.3 births per women. $\mathbf{C}_{m}, \mathbf{C}_{c}, \mathbf{C}_{i}$ and $\mathbf{C}_{a}$ are indices measuring the fertility inhibiting effect of marriage, contraception, post-partum infecundability and abortion respectively.

\section{Estimation of Index of Marriage}

The index of marriage measures the reduction in fertility that is caused by the marriage. According to Stover, this index is intended to represent the effect of periods during which a woman is not sexually active. Since data on sexual activity are scarce, this index is often approximated by the proportion of women 15-49 that are married. This index can be determined as follows. 


$$
C_{M}=\frac{T F \mathrm{R}}{T M}=\frac{\sum f(a)}{\sum f(a) / m(a)}
$$

Where $\mathrm{m}(\mathrm{a})$ equals the current proportion married among females, by age, $f(a)$ is a schedule of age-specific fertility rates. It takes the value 0 if nobody is married and the value 1 if all women are married during the entire reproductive period.

\section{Estimation of Index of Contraception}

The index of contraception is intended to describe the fertility-inhibiting effects of contraceptive use. The index of contraception was specified by Bongaarts as follows.

$$
\mathrm{C}_{c}=1-1.08 \times \mathrm{u} \times \mathrm{e}
$$

Where, $u$ is contraceptive prevalence among married women and $e$ is the average effectiveness of contraception and 1.08 is the adjustment factor, which is designed to remove the infecund women from the equation. If no contraception is practiced, Cc equals 1.0, and if all nonsterile women in their reproductive ages are protected by 100 per cent effective contraception, then $\mathrm{Cc}$ equals zero. The indices use the effectiveness by Trussell (2011).

\section{Estimation of Index of Induced Abortion}

The index of induced abortion determines the inhibiting effects of induced abortion on fertility. This index can be estimated by using the following formula:

$$
C_{a}=\frac{T F R}{T F R+A}=\frac{T F R}{T F R+b \times T A}=\frac{T F R}{T F R+0.4(1+\mu}
$$

Where $u=$ prevalence of contraceptive use and $\mathrm{TA}=$ total abortion rate. It takes the value 1 in the absence of induced abortion and the value 0 when all the pregnancies are aborted. In this study, due to lack of data and abortion is not legal in Sudan, except in the case of rape or risk to the mother's life, it is rarely performed in public institutions, we consider the value of this index to be one.

\section{Estimation of Index of Post-Partum Infecundability}

The index of post-partum infecundability measures the inhibiting effects of postpartum amenorrhea and breastfeeding on fertility. It is the ratio of the birth intervals due to the absence of breastfeeding and the presence of the breastfeeding. In the absence of breastfeeding, the birth interval is on an average about 20 months, the sum of 1.5 months of post-partum infecundability due to the absence of breastfeeding, 7.5 months of waiting time to conception, 2 months due to spontaneous intrauterine mortality and 9 months for a full-term pregnancy. In the presence of breastfeeding, the average birth interval, approximately 18.5 months $(7.5+2+9)$, plus the average duration of postpartum infecundability. This index can be estimated as follows.

$$
C_{i}=\frac{20}{18.5+i}
$$

Where $\mathrm{i}=$ the average duration of postpartum infecundability. If the direct estimate of $\mathrm{i}$ is not possible, then according to Bongaarts, it can be estimated as follows.

$$
i=1.753 \exp \left(0.1396 \beta-0.00187 \beta^{2}\right)
$$

Where the $\beta=$ average duration of breastfeeding. 
According to the Bongaarts aggregate model (Bongaarts, 1978), the difference between TF and the estimated TFR is the total inhibiting effects of the proximate determinants at a certain point of time. To estimate the relative contribution of each of the proximate determinants to the total inhibiting effect (i.e. TF - TFR), Wang, et.al. (1987) deduced a simple equation by multiplying the total inhibiting effects by the proportion of the logarithm of each index to the sum of the logarithmof all indices. For example, the magnitude of the relative fertility inhibiting effect of marriage is given by;

$\mathrm{TF}-\mathrm{TFR}($ estimated $)=\frac{\log C_{m}}{\left(\log C_{m}+\log C_{c}+\log C_{a}+\log C_{i}\right)}$

Similarly, the magnitude of the relative inhibiting effect of contraception and postpartum infecundability. Information of indices of Bongaarts model was done for selected background characteristics such as residence, education, wealth, state, and region. Below is the presentation of the results obtained.

\section{Results}

\section{Background Characteristics}

The total population of women sampled in SMICS was 18,302 women. Of these, 32.7 per cent living in urban areas while 67.3 per cent living in the rural areas. Majority of the women were aged below 20 years. About 20 per cent of the women were aged below 20 years. The smallest age group, those aged between 45-49 years, comprised of about 7.2 persen of the population. The general pattern of population in each age group was observed to decreasing as the age increased. The mean age was 28 years. This is synonymous with a young population. About 65.7 per cent of the population was recorded as married. A further break down showed that 29.3 per cent of the population had never been married. The remained of the population ( 5 per cent) were recorded as formerly married, widowed and divorced. About 68 per cent of the population had never attended school or attended only primary school while approximately 9.4 per cent had attended higher education which this means most of the population were not educated. The results on wealth index indicate that the poorest population accounted for 18.3 per cent of the population while the richest accounting for 19.6 per cent. This indicates that majority of the population are middle wealth status with 62.2 per cent. Majority of women residing in Darfur region by 25.9 per cent followed by Central region 24.7 per cent, while the lowest region was Khartoum with 6.4 per cent. However, regarding patterns and levels of fertility, results show normal fertility pattern along age groups whereby fertility increases gradually from the early ages, peak between age groups 25-29 and 30-34 and thereafter following a downward trend. This is consistent with the expected pattern. Moreover, according to the 2014 SMICS results, the total fertility rate is 5.0 children/women.

Duration of post-partum infecundability, as reported in the SMICS report, was 21.2 months and this is what was used in the computation to represent the average duration of postpartum fecundability. With regard to abortion data, abortion index was indicated as 1 to indicate the absence of abortion data. Moreover, induced abortion is illegal in Sudan, only in cases of rape and when the woman's life is at risk (Elamin, et.al., 2017; Kinaro, et.al., 2009). 
Fertility-Inhibiting Effect of The Proximate Determinants

To estimate the proportionate fertilityinhibiting effects of the four major proximate determinants of fertility and their relative role in the reduction of fertility in Sudan using SMICS 2014, the Bongaarts aggregate model is used and the results are showed in Table 1. The first panel of Table 1 presents a summary of measures that are needed for computing the model indices. The lower the estimated value of index, the greater is the fertility-reducing impact. As mentioned earlier that there is no data available on induced abortion in Sudan and it is not widely practiced in Sudan. This because the religious, social and legal prohibition (Elamin, et.al., 2017; Kinaro, et.al., 2009), the value of abortion $\mathrm{Ca}$ is assumed to be 1 indicating that it has no fertility-inhibiting effect in Sudan.

The results of model indices analysis show that in 2014, postpartum infecundability has the largest contribution to fertility reduction, accounting for $40 \%\left(1-C_{i}=40\right)$ reduction in total fecundity (TF). The second most important fertility reducing determinant was marriage, accounting for 36 per cent (1$\mathrm{C}_{\mathrm{m}}=36$ ) reduction in actual fertility levels below marital fertility. Contraception has relatively lower fertility-reducing effect, accounting for 12 per cent $\left(1-C_{c}=12\right)$ reduction of natural fertility relative to marital fertility.

\section{Magnitude The Inhibiting Effect of Proximate} Determinants

Figure 1 presents the magnitude of the inhibiting effect being accounted for by each proximate determinant of fertility at 2014 . The results in Figure 1 shows the contribution in absolute terms of each proximate determinant to fertility reduction. The largest contributors to fertility reduction were postpartum infecundity (referred to as breastfeeding in figure), followed by marriage. Post-partum infecundity accounted for a reduction of 4.7 children from the biological maximum of 15.3 children per woman. Marriage accounted for reduction of 4.2 children, while contraception accounted for a reduction of 1.2 children.

Table 1 Fertility Inhibiting Effect of Major Proximate Determinants, Sudan, 2014

\begin{tabular}{lc}
\hline Proximate determinants & Estimates values \\
\hline Proximate determinants measures & \\
Total fertility rate (TFR) & 5.2 \\
TMFR & 7.6 \\
Contraceptive prevalence rate $(\mathrm{u})$ & $12.2 \%$ \\
Contarceptive use effectiveness $(\mathrm{e})$ & 0.91 \\
Median duration of breastfeeding & 21.2 \\
Bongarrts model indices & \\
Index of marriage $(\mathrm{Cm})$ & 0.64 \\
Index of contraception $(\mathrm{Cc})$ & 0.88 \\
Index of postpartum infecundability $(\mathrm{Ci})$ & 0.60 \\
Index of abortion* $(\mathrm{Ca})$ & 1.00 \\
Combined inhibiting effect $\left(c_{m} \times c_{c} \times c_{i} \times c_{a}\right)$ & 0.34 \\
Total fecundity (TF) & 15.3 \\
Predicted TFR & 5.2 \\
\hline
\end{tabular}

Source: Created by author, 2018 
Mustafa Elnagi Elsamani Hassan, Sukamdi, and Agus Joko Pitoyo

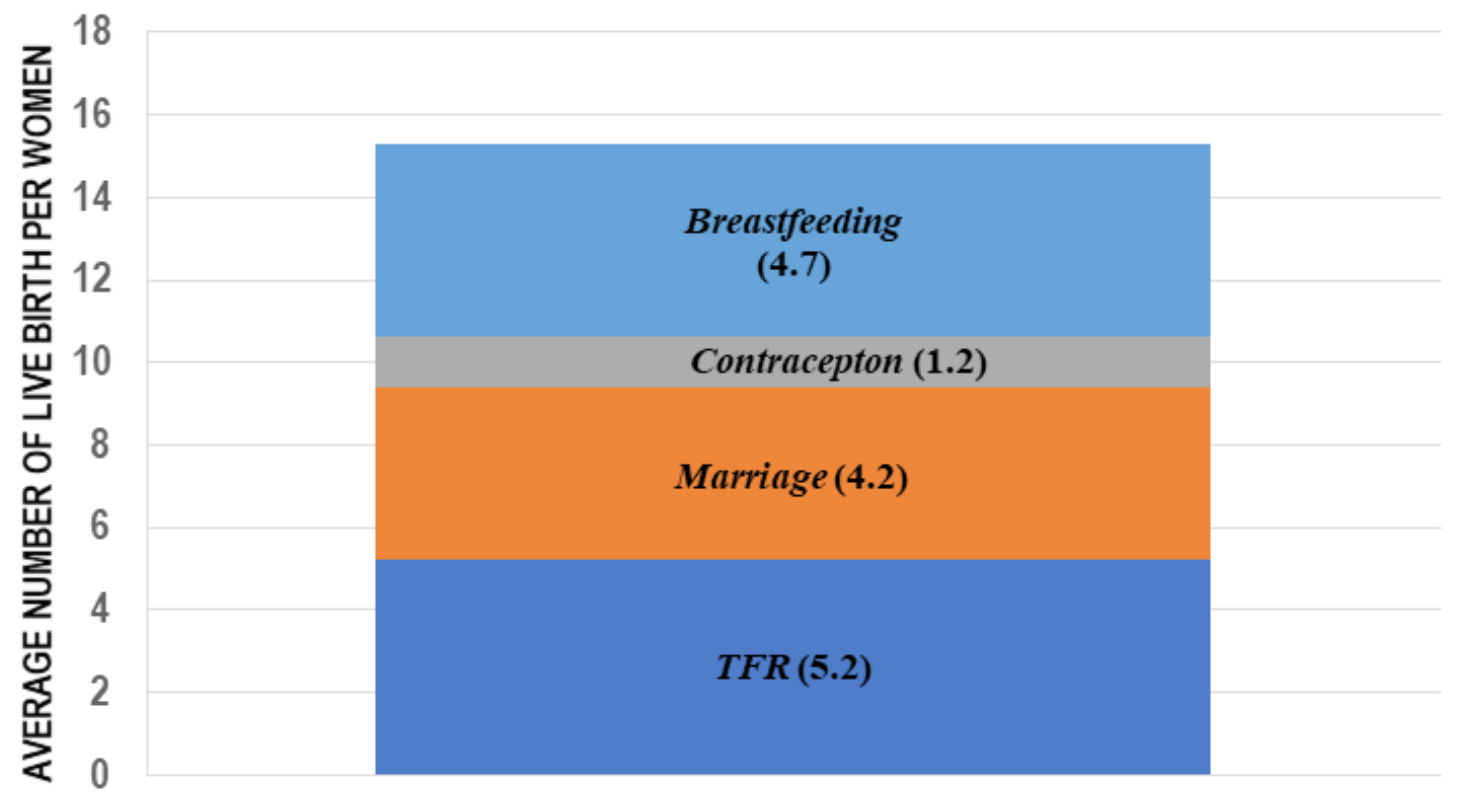

FERTILITYEFFECT

$\square$ TFR Marriage $\square$ Contracepton $\square$ Abortion $\square$ Breastfeeding

Source: Created by author, 2018

Figure 1 Effects of the Proximate Determinants on the Total Fertility Rate

In term of percentages, the impact of each proximate determinants is displayed in Table 2. Post-partum infecundability accounted for 30.72 per cent, marriage 27.45 per cent, contraception 7.84 per cent in reduction fertility from its biological maximum (15.3 children/women). This suggests that women who breastfed longer and married women contributed the most towards fertility reduction.

\section{Fertility Differentials}

The impacts of the marriage, breastfeeding and contraceptive indices on fertility with regard to residence, education, wealth and region are displayed in Table 3. With regard to residence, the effect of marriage was higher in urban areas (48 per cent) than in rural areas (31 per cent), while

Table 2 Estimated Proximate Determinants Indices and Their Impact on Fertility Reduction for Sudan, 2014

\begin{tabular}{lcc}
\hline Proximate determinants indices & $\begin{array}{c}\text { Estimates } \\
\text { values }\end{array}$ & $\begin{array}{c}\text { Impact on fertility } \\
\text { reduction }\end{array}$ \\
\hline Index of marriage $(\mathrm{Cm})$ & 0.64 & 27.45 \\
Index of contraception $(\mathrm{Cc})$ & 0.88 & 7.84 \\
Index of postpartum infecundability $(\mathrm{Ci})$ & 0.60 & 30.72 \\
Index of abortion* $(\mathrm{Ca})$ & 1.00 & 0.00 \\
Combined inhibiting effect $\left(C_{m} \times C_{c} \times C_{i} \times C_{a}\right)$ & 0.34 & 66.01 \\
TF-TFR (estimated) & & 10.1 \\
\hline
\end{tabular}

Source: Created by author, 2018 
the effect of post-partum infecundability was not significant by (40) rural areas and (39 per cent) in urban areas. The effect of contraception was higher in urban areas (20 per cent) than in rural areas (9 per cent). Marriage contributed more to fertility reduction in urban areas than in rural areas, while post-partum infecundability contributed more to fertility reduction in rural areas than in urban areas by only 1 per cent.

An inverse relationship was observed, with regard to education, between marriage and postpartum infecundability. As education level increased, the effect of marriage increases, while the effect of post-partum infecundability reduces. It was observed that, among women with no education, post-partum infecundability (39 per cent) contributed more towards fertility reduction than marriage (22 per cent), whereas among women with higher education marriage (67 per cent) contributed more towards fertility reduction than postpartum infecundability (37 per cent).

This relationship was also observed with respect to wealth. As the wealth status improved, the effect of marriage increased, while the effect of postpartum infecundability had no clear pattern (no different) by wealth status. It was observed that among the poorest women, marriage (27 per cent) contributed more towards fertility reduction, whereas among the richest women marriage (50 per cent) contributed more towards fertility reduction. With contraception, however, the impact increased with increase in both education and wealth.

The effect of contraception on fertility was higher among women with higher education (30 per cent) than among those with no education (4 per cent). Similarly, the effects of contraception were higher among the richest women (28 per cent) than among the poorest women (3 per cent).
The diversity of marriage, contraceptive and breastfeeding indices is apparent geographically, as indicated in Table 3 and Figure 2. Regard to marriage and contraceptive, results show that the states that have a higher impact on fertility reduction than national level were recorded in River Nile, Khartoum, Northern, Gezira, North Kordofan and Sinnar respectively whereas, regard to contraceptive, Khartoum, Northern, River Nile, White Nile, North Kordofan and Sinaar respectively. Thus, in same states, both marriage and contraceptive contributed more towards fertility reduction than national rate excluding Gezira state in marriage and white Nile in contraceptive. With regard to breastfeeding, the states that contributed more towards fertility reduction than the national rate recorded in River Nile, Red Sea, West Kordofan and Central Darfur.

Similarly, to indices of marriage, postpartum infecundability, and contraception, TFR shows the same pattern, its shows that TFR was higher in rural areas than urban areas. Based on births in the one year preceding the survey, rural women have on average 1.9 more births than women in urban areas. The largest fertility differentials are associated with education level and wealth. An inverse relationship was observed, as education level and wealth increase, the TFR decrease. The TFR was 7.0 for women with no education and 2.3 for those with higher education, a difference of 4.7 births whereas, for poorest women 6.6 births and 3.4 for richest women, a difference of 4.2 births. The diversity in TFRs is apparent geographically, as indicates in Table 3 and Figure 3, TFR was higher than national TFR in Darfur and Eastern region states excluding Red Sea while its observed lower than national TFR in Northern, Central and Kordofan region states excluding Blue Nile state. 
Table 3 Estimated Indices for the Principle Determinants by Selected Background Characteristics

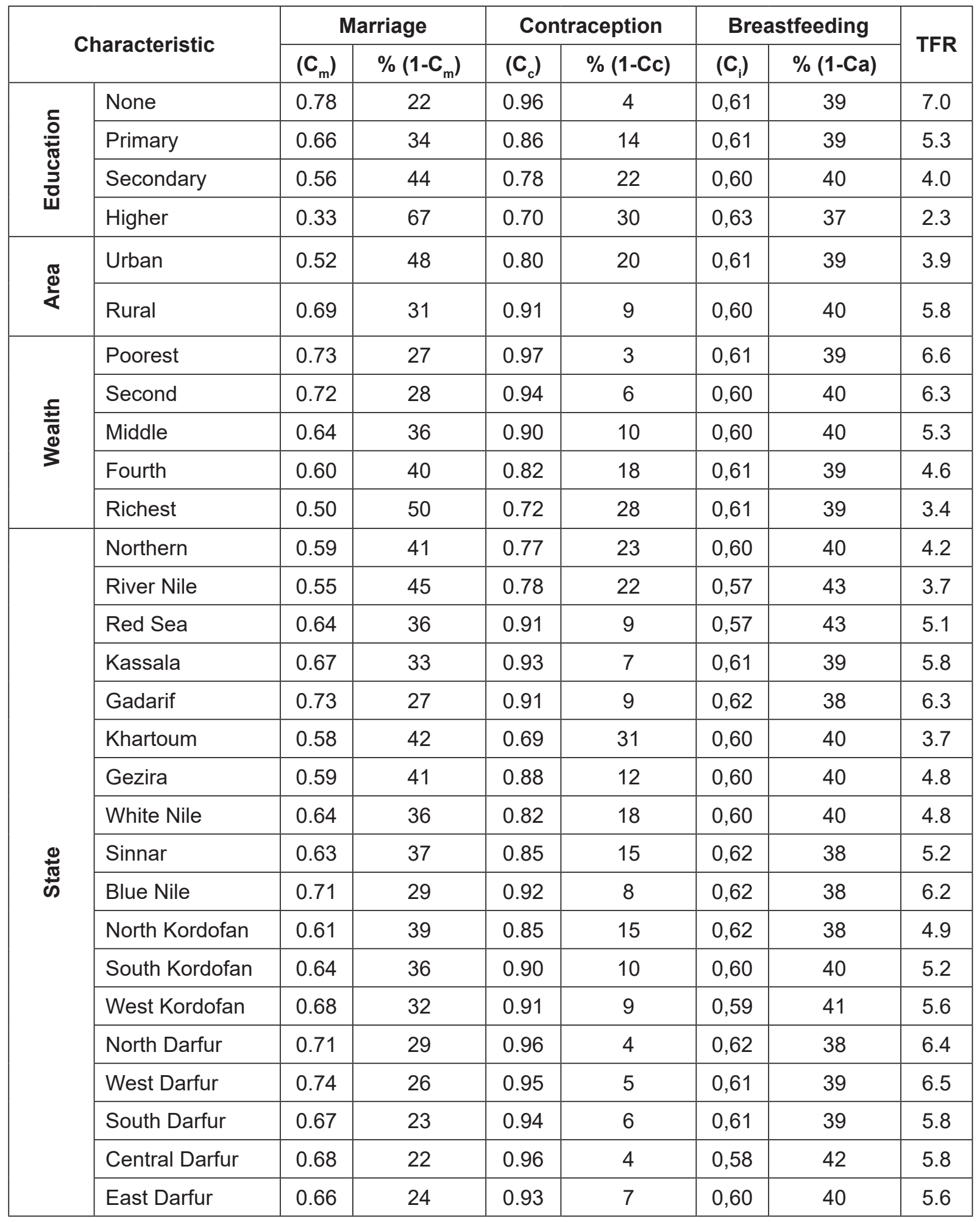

${ }^{*}$ Index of abortion could not be estimated and was assumed as 1.00 due to unavailability of data on abortion

Source: Created by author, 2018 


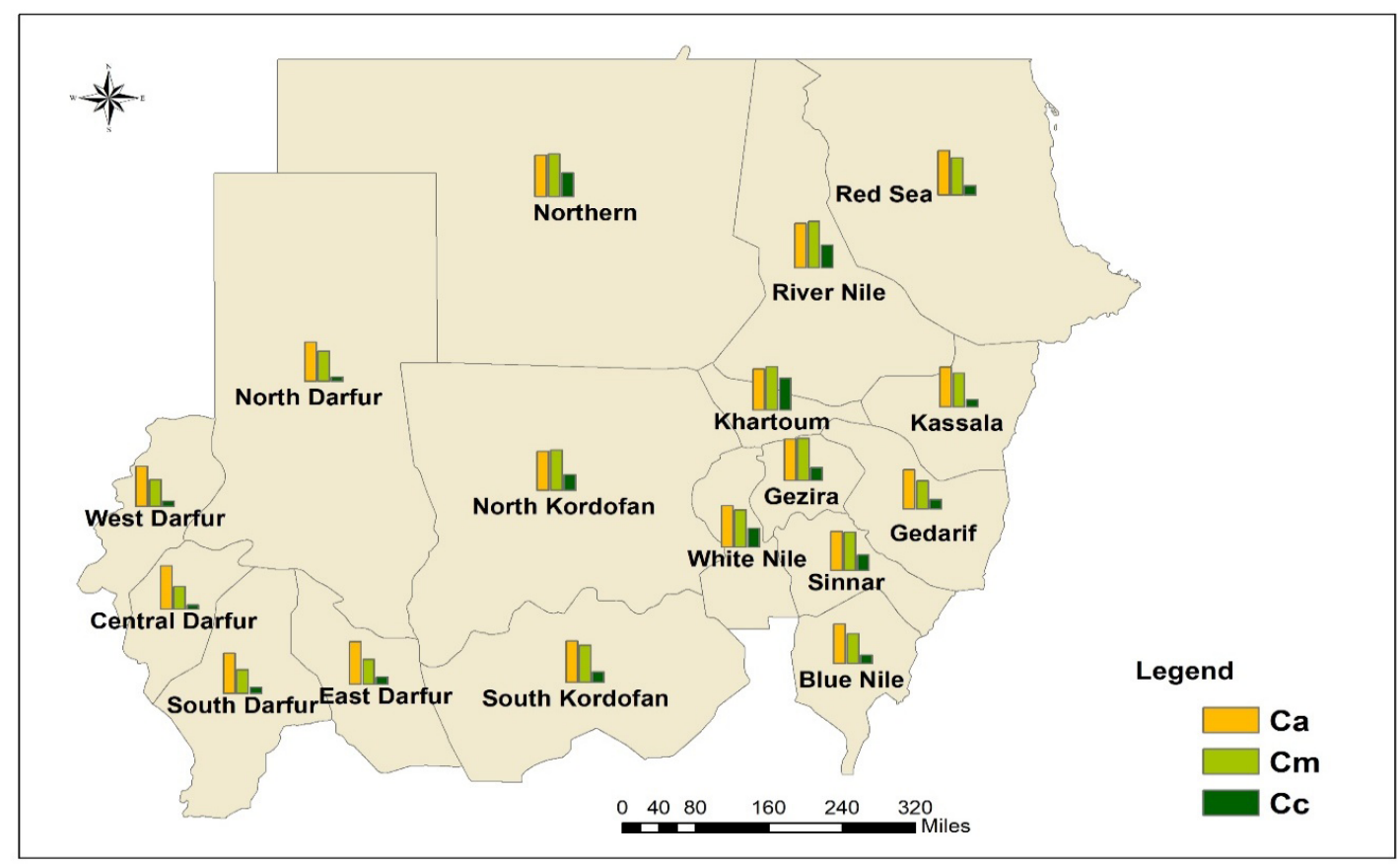

Source: Created by author, 2018

Figure 2 Percentage of Marriage, Contraceptive and Breastfeeding Indices by State

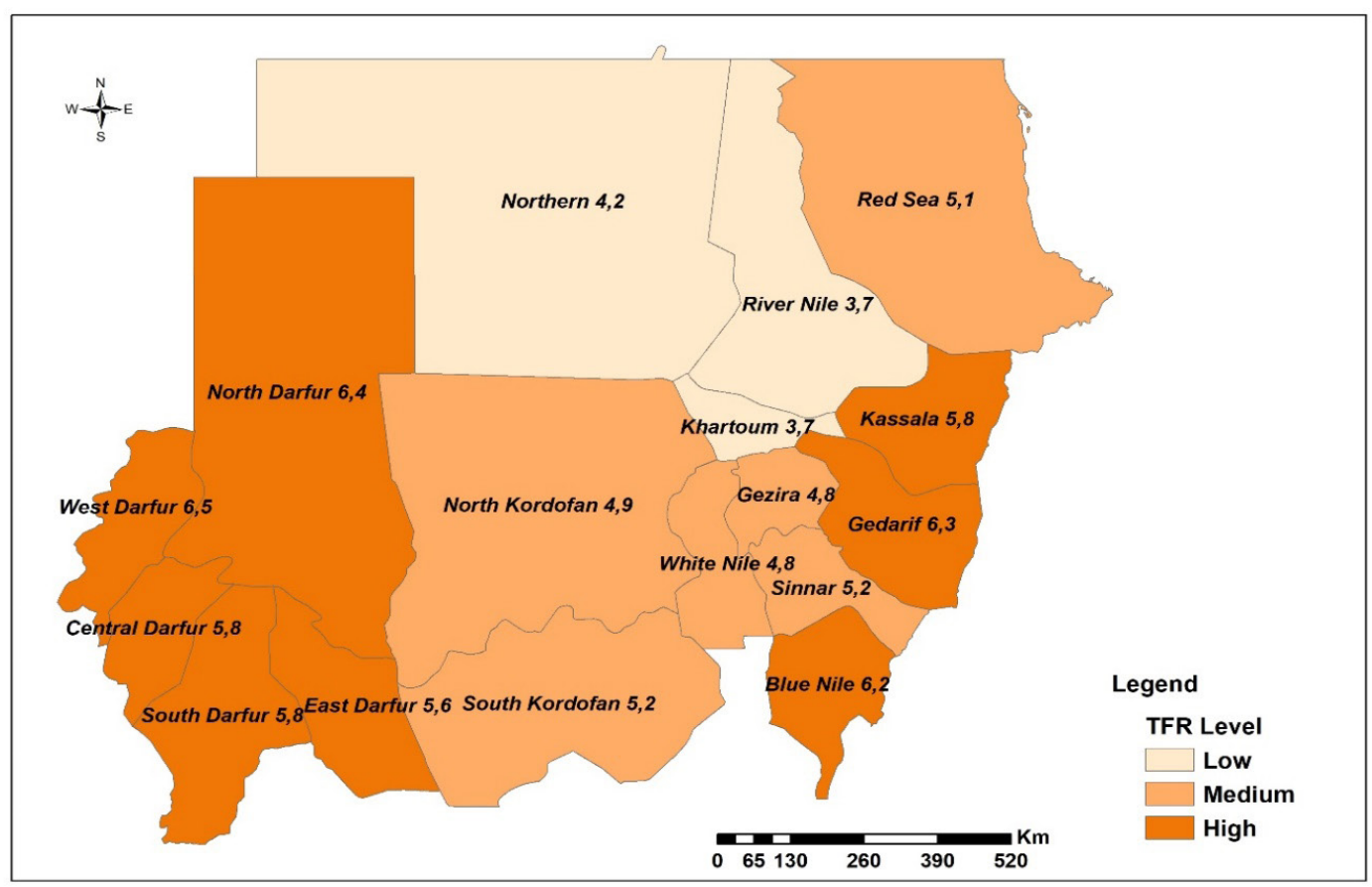

Source: Created by author, 2018

Figure 3 Estimation of Total Fertility Rates by State 


\section{Discussion}

The aim of this study was to examine level, patterns, and differentials of fertility using the data from the most recent national-level survey in Sudan (MICS), 2014, focusing on the relative contribution of the proximate determinants in such fertility reduction. The empirical analysis shows that total fertility rate was 5.2 births per women. This by far one of the highest fertility level in world and more than the average of TFR in Sub-Sahara countries in Africa (UN, 2015). The comparable high fertility can be seen in another country in Africa (e.g Mozambique, Somalia, Uganda, Chad) and Timor Leste in South Eastern Asia. However, the analysis of current fertility by age cohorts has declined consistently in all age cohorts compare the fertility rates in previous MICS survey 2010. The decline is steepest among young women aged 1529 years. However, the decline in fertility is relatively slower among the women in old age 30-49 years, this indicates that declining in fertility rates mainly due to delayed age at first marriage.

The analysis of proximate determinants of fertility suggests that rising age at first marriage, and continued high duration of postpartum infecundability and use of contraceptive methods consistent with the reduction of fertility in Sudan. The analysis suggests that post-partum infecundability and marriage played the most prominent part in reducing natural fertility. Contraception had the least fertility inhibiting effect. The results of Bongaarts model show the changes in the contribution of the proximate determinants of fertility, namely, marriage, contraception, and postpartum infecundity. Results also quantify the contribution of each proximate determinant to fertility reduction in Sudan. While Eltigani (2000), Mahfouz (2006) and
Adam (2007) found that marriage had the most fertility reducing effect on fertility, followed by postpartum infecundity and contraceptive, this study found that postpartum infecundability has emerged as the most prominent inhibitor of fertility in Sudan (30.7 per cent or 4.7 births), with marriage the second most important inhibitor (27.5 per cent or 4.3 births) and contraception the third (7.8 per cent or 1.2 births).

Similarly, Lailulo, et.al. (2017) in Ethiopia found that post-partum infecundity had the largest fertility reducing inhibitor. Analysis of data from the World Fertility Survey (WFS) and Demographic and Health Survey (DHS) also found that index of post-partum infecundability is generally the most significant inhibitor of fertility. Although prolonged breastfeeding and post-partum abstinence are not universal in sub-Saharan Africa, they generally play an important role in spacing births and reducing total fertility (Jolly \& Gribble, 1993). This suggests that prolonged breastfeeding has the potential to contribute to fertility reduction. In India, it was found that, in the absence of breastfeeding after menstruation resumes, the risk of conception increases (Bongarrt, 1983). Singh, et.al. (1993) suggested that breastfeeding after menstruation resumes plays a significant role in the proximate determinants to reduce fertility. Therefore, it can be argued that promotion of universal breastfeeding among women could contribute significantly to reducing fertility. In study in Iran, Bayyenat (2014) refers the high breastfeeding in Arab countries to Islamic beliefs. He argues that Islam recommended every mother to breastfeed her children up to the age of two years if the lactation period was to be completed. This may explain the reason for high breastfeeding practice in Sudan. This argument supported by Saaty research (2015) argues that breastfeeding practices, 
including exclusive breastfeeding, are shaped by cultural and religious values and beliefs.

The analysis also showed that marriage was the second most influential factor with 27.5 per cent in reducing fertility. This related to the majority of women in MICS reported married by 65.7 per cent. Mahfouz (2006) argues that marriage in Sudan is almost universal, and it is the only union through which stable cohabitation of couples takes place. The incidence of children born outside marriage is extremely rare. Furthermore, many studies across the world found that marriage had the highest fertility inhibiting effect fertility reduction from its biological maximum of 15.3 children per woman (Islam, 2017; Palamuleni, 2017; Chola, et.al., 2016; Hossain, et.al., 2013, Tey, et.al., 2012; Moses \& Kayizzi, 2007). This suggests that marriage played an important role in fertility reduction.

Through contraception shows relatively lower fertility-reducing effect among proximate determinants, but it's not significant with only 7.8 per cent in fertility reduction. This is true since MICS 2014 showed that only 12.2 per cent of responses women were current users of contraceptive. Similar findings were observed in other studies (Islam, 2017; Choha and Michelo, 2016 \& Moses \& Kayizzi, 2007). Thompson (2007) in his paper "Poverty, Development and Women" argues that Africa characterized by high rate of lack to contraceptive access reaching 57 per cent. Regarding the reasons for low contraceptive use in Sudan, Ahmed, et.al. (2015) argues that utilization rate of family planning methods in Sudan is affected by several barriers, such as geographic accessibility, affordability, perceptions, and socio-cultural conditions. Another study argues that impacts the decision to use family planning services is related to the unequal power relations that exist between men and women (Mustafa, et.al., 1984).
Similarly, Ahmed (2016) argues that men often play the dominant role in decisions vital to the reproductive health of women. However, family planning professionals assume that men take less interest in matters that concern reproduction.

Analysis of education and wealth showed an inverse relationship. This is similar to findings by Chola \& Michelo (2016); Mahjabeen and Khan (2011) and analysis of the World Fertility Survey and Demographic and Health Survey (Jolly \& Gribble, 1993). This could be attributed to the effects that education and wealth have on fertility. Various studies have shown that education (Karakaya, 2014; Adhikari, 2010 and Kalule-Sabiti, 1992) and wealth (Adebowale, 2014 and Weerasinghe, et.al., 2002) have an effect on fertility. With regard to breastfeeding, findings showed there no clear differences observed by education and wealth, although increasing with education also remained the lowest. Furthermore, regarding the place of residence, results showed that all indices was high in urban areas and lower in rural areas.

The analysis of regional differentials of total fertility rate shows a significant difference between states and regions in Sudan. Analysis shows that Darfur states relatively have high TFR compare other states followed by Kordofan and Eastern states. This could be attributed to the effect that low level of socio-economic condition. For example, the data MICS 2014 show that 35.4 per cent of women with no education and 60 per cent of poorest women residing in Darfur states. This opposite situation in northern region states were only 0.7 per cent poor women and 2.9 per cent women were had no education. Mohammed (2007) in his study argues that the reason of high fertility in Darfur states and region refer to high twin birth rate, high poverty, early marriage, together with illiteracy and low level of contraceptives practice. 
This study is not without limitation. First, induced abortion data was not available and therefore not included in the empirical analysis in this study. Availability of this data may change the outcome of this study. Second, this study used 2014 MICS, and this is the most recent data available in Sudan. This may have implication in the similar studies on more recent data may yield different results from the results presented in this study. Furthermore, this study focused on women and did not include men which play important role in fertility preference. This bearing on fertility level particularly in rural areas than urban areas. Although limitation presented above, various conclusions and recommendation can be drowned.

\section{Conclusions and Recommendation}

Fertility has a key role on the change in the socio-economic condition of a country. Understanding the level, pattern and nature of fertility, could help decision makers for policy formulation and building strategies and programs. From analysis and discussion above its clear that proximate determinants play an important role in influencing fertility and their influence has been well documented worldwide. An examination shows that postpartum infecundability has the largest effect in reducing fertility in Sudan followed by marriage which appears to play an important role in fertility reduction from its biological maximum. The lowest effect toward fertility reduction was contraceptive (contraceptive was very low at the time of survey 12 per cent), the lowest prevalence of contraceptive use in Sudan needs further research to investigate utilization of family planning services in Sudan, particularly in marginal states and regions like Darfur. The analysis also shows that significant differences between education level, wealth status, and place of residence, and fertility. This means that the increase in education levels, especially higher education, improve the wealth status and living in urban areas seem to have a great influence toward fertility education in Sudan. Also, it agreed that there is a regional fertility differential associated with social and economic development in the different regions and states in Sudan.

Based on the findings and discussion in this study the following recommendation can drown. First, post-partum infecundity, an inhibitor of fertility, has the potential to contribute significantly to fertility reduction. Promotion of breastfeeding can aid in fertility reduction. With campaigns focussing on breastfeeding children for 2 years and also on the benefits of breastfeeding to child development that is currently being conducted, the effects that breastfeeding has on fertility could be a positive "side-effect" as it will contribute to fertility management. Therefore, a continuation of these messages can prove vital in fertility management. Second, marriage as an institution contributes greatly to fertility because almost all of the children are born among married women. Encouraging contraception usage, particularly modern methods of contraception, can greatly impact on the existing high fertility rates through inhibiting fertility among married women. Also, steps against child marriage should be taken into account strictly, to minimize the marriage below 18 years, particularly in rural areas. Third, family planning services must be made available to every interested family and advocacy must be launched in order that it becomes a social routine mix in family life. Fourth, based on the inverse relationship between fertility and education, and fertility and wealth, enhancing women's education levels and wealth status can contribute to fertility reduction. Finally, there is an urgent 
need for comprehensive population policy in which all country strategies are included in order to control the population growth and managing fertility, without neglecting the role of mortality and migration. Lack of such targeted intervention, population growth will remain a challenge in Sudan.

\section{References}

Adam, Ismail Abakar. 2007. "Determinants of Fertility In Northern Sudan". Thesis: Khartoum University. Available at: http://khartoumspace.uofk.edu/ bitstream/handle/123456789/ 13297/ Determinants $\% 20$ of20Fertility $\% 20$ In $\% 20$ Northern\%20Sudan.pdf?sequence=1.

Adebowale, S. A. and Palamuleni, M. E. 2014."Childbearing Dynamics among Married Women of Reproductive Age in Nigeria: reaffirming the role of education," African Population Studies, 27 (2), 301318.

Adhikari, R. 2010. "Demographic, socioeconomic, and cultural factors affecting fertility differentials in Nepal". BMC Pregnancy and Childbirth, 10.

Ahmed W. A. M, Shokai, S. B., Abdul Khair, I. H., Boshra, A. Y. 2015. "Factors affecting utilization of family planning services in a post-conflict setting, South Sudan: a qualitative study". AIMS Public Health, 2 (4), 655-66.

Ahmed, W. A. Mohammed. 2016. "Effect of Innovative Contraceptive Program on Family Planning Utilization Rate in Khartoum, Sudan: A Randomized Controlled Trial". GMJ. 5 (1), 41-47.

Bayyenat, S., Amirhosein, S., Hashemi, G., Purbafrani, A., Saeidi, M. \& Khodaee, G. H. 2014. "The Importance of Breastfeeding in Holy Quran". International Journal of Pediatrics, 2, N4-1, Serial No.10, 339-347.
Bongaarts, J. 1982. "The Fertility-inhibiting Effects of the Intermediate Fertility Variables". Planning, 13 (6/7), 179-189.

Bongaarts, J. and Potter, R.G. 1983. "Fertility, Biology, and Behaviour: An Analysis of the Proximate Determinants". New York: Academic Press,13 (2), 323-334.

Bongaarts, John. 2015. "Modeling the Fertility Impact of the Proximate Determinants: Time for a tune-up". Demographic Research, 33, article 19, 535-560.

Central Bureau of Statistics (CBS), UNICEF Sudan. 2016. "Multiple Indicator Cluster Survey 2014 of Sudan, Final Report". Khartoum, Sudan.

Central Bureau of Statistics. 2012. "National Report of The Sudan Household Health Survey - Second Round 2010". Khartoum, Sudan.

Chola, Mumbi and Michelo, Charles. 2016. "Proximate Determinants of Fertility in Zambia: Analysis of the 2007 Zambia Demographic and Health Survey". Hindawi International Journal of Population Research, pp.1-7.

Chola, Mumbi J. 2013. Determinants and Patterns of Fertility in Zambia. University of Zambia. Zambia.

Davis, K. and Blake, J. 1956. "Social Structure and Fertility: An Analytical Framework". Economic Development and Cultural Change, 4 (2), 211-235.

Department of Statistics. 1982. Sudan Fertility Survey 1979: Principal Report. Vol 1 \& 11. Khartoum.

Department of Statistics. 1992. Sudan Demographic and Health Survey 19891990. Khartoum. Available at: https:// dhsprogram.com/pubs/pdf/fr36/f r36.pdf.

Dharmalingam, A\& Rajan, Sowmya \& Morgan, S. Philip. 2015. "The Determinants of Low Fertility in India”. Demography, 51(4), 1451-1475. 
Elamin, Wafa.; Fazari, A. B. \& Elmusharaf, K. 2017. "Qualitative Study Exploring Women's Experiences of Unsafe Abortion in Sudan". Open Journal of Social Sciences, 5, 149-158.

Elnagar, S.; Ati, H. A.; Eltigani, L. \& Mukhtar, H. M. 2011. An Update of Reproductive Health, Gender, Population and Development Situation in Sudan, 2011. UNFPA, Sudan.

Eltigani, Eltahir. E. 2000. "Understanding Fertility Decline in Northern Sudan: An Analysis of Determinants". Genus, 56 (1/2), 115-132.

Hossain, F. \& Karim, R. 2013. "Determination of Total Fertility Rate of Bangladesh using Bongaarts Model". J Biomet Biostat, 4 (5), 176.

Ibnouf, A.H \& Borne, V. D \& Maarse, J.A.M. 2007. "Utilization of Family planning Services by Married Sudanese Women of Reproductive Age". Eastern Mediterranean Health Journal, 13 (6), 1372-1381.

Islam, Mazharul. M. 2017. "Rapid Fertility Decline in Oman: Understanding the Role of Proximate Determinants". Middle East Fertility Society Journal. http://dx.doi. org/10.1016/j.mefs.2017.04.007.

Islam, R., Islam, N., Rahman, M., Hossain, G. \& Islam, R. 2015. "Fertility Situation in Bangladesh: Application of Revised Bongarrts Model". Science and Technology Journal, 5 (2), 33-38.

Jolly CL; Gribble JN. 1993.The Proximate Determinants of Fertility. National Academy Press, pp.68-116.

Kalule-Sabiti, I. 1992. "Socio-economic factors affecting fertility in Kenya". South African Journal of Sociology, 23 (2), 46- 52.

Karakaya, E. 2014. "Socioeconomic determinants on fertility rate at an aggregate level: a linear regression model for Turkish provinces". Public Knowledge Journal, 6, 1-6.
Kinaro, J., Ali, T. E. M., Schlanggen, R. \& Mark, J. 2009. "Unsafe abortion and abortion care in Khartoum, Sudan". Reproductive Health Matters 17(34), 71-77.

Lailulo, Y. A. and Susuman, Sathiya. 2017. "Proximate Determinants of Fertility in Ethiopia: Comparative Analysis of the 2005 and 2011 DHS". Journal of Asian and African Studies, pp.1-16.

Mahfouz, Mohamed Salih. 2006. "Fertility in Northern Sudan ( 1979-1999): Levels, Trends and Determinants". XXVI International Population Conference of the IUSSP. Available at: https://www. researchgate.net/publication/236008666_ Fertility_in_Northern_Sudan_1979-1999_ levels_trends_and_determinants.

Mahjabeena, T. and Khan, I. A. 2011. "Analyzing Bongaarts model and its Applications in the Context of Bangladesh". 19th International Congress on Modelling and Simulation. Perth, Australia.

Majumder, N. and Ram F. 2015. "Explaining the Role of Proximate Determinants on Fertility Decline among Poor and NonPoor in Asian Countries". PLoS ONE 10(2): e0115441. doi:10.1371/journal.

Mohammed, A. F. Ijlal. 2007. "Trends of Human Fertility in North Darfur: Case Study of Elfasher Locality in Periods between 1993 to 2005". Thesis. Khartoum University. Sudan.

Moses L. Y. A. \& Kayizzi, J. B. 2007. "Using the Bongaarts Model in Explaining Fertility Decline in Urban Area of Uganda". In Proceedings of the 5th African Population Conference, Arusha, Tanzania.

Mustafa MA, Mumford SD. 1984. "Male attitudes towards family planning in Khartoum". Sudan. Journal Biosoc Sci. 16(4), 437-49.

Palamuleni, Martin E. 2017. "Determinants of Fertility Decline in Namibia: An Analysis of the Proximate Determinants". Bangladesh e-Journal of Sociology, 14 (2), 41-63. 
Saaty, A. H.; Cowdery, Joan \& Karshin, Christine. 2015. "Practices of Breastfeeding among Arab Mothers Living in the United States". World Journal of Medical Sciences, 12 (2), 183-188.

Singh, K. K.; Suchindra, C. M.1993. "Effects of breastfeeding after resumption of menstruation on waiting time to next conception". Human Biology, 65 (1), 7186.

Stover, John. 1997. "Revising the Proximate Determinants of Fertility Framework: What have we Learned in the Past Twenty Years". Studies of Family Planning, 29 (3), 255-67.

Tey, N. P; Ng, S. T.; and Yew, S. Y. 2012. "Proximate Determinants of Fertility in Peninsular Malaysia". Asia-Pacific Journal of Public Health, 24(3), 495-505.

Thompson, J. E. 2007. "Poverty, development, and women: Why should we care?" Journal Obstet Gynecol Neonat Nurs. 36, 523-530.

Trussell J. 2011. "Contraceptive failure in the United States”. Contraception, 83, 397-40.

United Nations, Department of Economic and Social Affairs, Population Division. 2017. World Population Prospects: The 2017 Revision, DVD Edition. Available at: https://esa.un.org /unpd/wpp/Download/ Standard/Population/.

United Nations, Department of Economic and Social Affairs, Population Division. 2015. World Fertility Patterns: The 2015 Revision, DVD Edition.

Wang, S.X., Yu-De, Chen, Charles, H.C., Chen, R.W., Rochat, L.P.C., Rider, R.V.1987. "Proximate determinants of fertility and policy implementation in Beijing". Studies Family Planning, 18, 222-228.

Weerasinghe, D. P., \& Parr, Nicholas J. 2002. "Effect of Wealth on Marital Fertility in Sri Lanka". Journal Health Population Nutrition, 20, 112-119. 